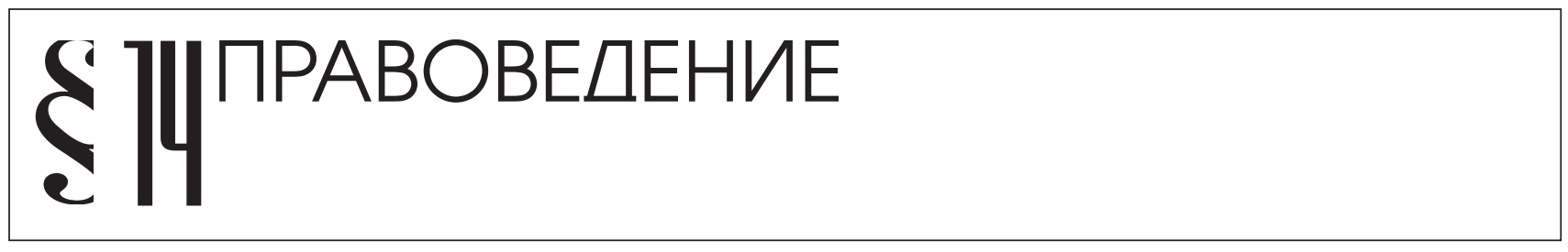

Васильченко А.И.

\title{
ЦЕНА И СРОК ЭНЕРГОСЕРВИСНОГО ДОГОВОРА
}

\begin{abstract}
Аннотация: В качестве предмета исследования выступают условия о сроке и цене энергосервисного договора. В ходе исследования осуществлен анализ положений Федерального закона «Об энергосбережении и повышении энергетической эффективности», ряда других нормативных актов в сфере энергосбережения и повышения энергетической эффективности, правоприменительная практика и доктринальные положения в указанной сфере. $B$ рамках исследования автор рассматривает проблемы согласования условий ичене и сроке энергосервисного договора, проводит обзор различных моделей энергосервисного договора, в которых воплощается принцип зависимости иень энергосервисного договора от достигнутой величины экономии энергетических ресурсов. В статье используются как общенаучные, так и специильные правовые методы исследования, а именно, системный, логический, диалектический, исторический, структурно-функииональный, формально-юридический, сравнительно-правовой, метод правового моделирования, наблюдение и описание, анализ документов и другие методы научного познания. Цена энергосервисного договора не относится к числу его существенных условий и не подвергается государственному регулированию. Характерной особенностью энергосервисного договора следует считать возможность установления цены в зависимости от величины экономии энергетических ресурсов, достигнутой в результате осуществления энергосберегаюших мероприятий в рамках энергосервисного договора; указанная величина. в свою очередв. подлежит согласованию сторонами.Срок энергосервисного договора, наряду с предметом договора, относится к числу существенных условий. Для того, чтобы заключить договор, стороны обязаны установить срок, по истечении которого должна быть достигнута согласованная сторонами величина экономии энергетических ресурсов.
\end{abstract}

Abstract: The study concern the conditions on price and period of energy service contract. The article provides analysis of the provisions of the Federal Law "On Energy Saving and Greater Energy Efficiency", and other normative legal acts in the sphere of energy saving and higher energy efficiency, legal practice and doctrinal provisions in this sphere. Within the framework of the study the author evaluates the problems of coordination of clauses on price and period of energy service contract, providing an overview of various models of energy saving contract, which reflect the principle of dependency between the price of energy service contract and the amount of economy of energy resources. The article involves general scientific and special legal methods of study, namely, the author uses systemic, logical, dialectic, historical, structural-functional, formal legal, comparative legal methods, method of legal modeling, observation, description, analysis of documents and other methods of scientific cognition. The price of energy service contract is not among its fundamental conditions, and it is not regulated by the state. A specific feature of energy service contract is the possibility to establish the price depending on the amount of economy of energy resources as a result of energy saving activities within the framework of energy service contract. The said amount should be agreed upon by the parties. The period of energy service contract is among the fundamental conditions of the contract. In order to conclude a contract the parties should establish a period after which the parties should agree upon the amount of economy of energy resources.

Ключевые слова: Энергосервисный договор, чена договора, срок договора, существенные условия договора, энергосбережение, энергетическая эффективность, закон об энергосбережении, энергоресурсы, заключение энергосервисного договора, возмездное оказание услуг.

Keywords: Energy service contract, price of a contract, period of a contract, fundamental conditions of a contract, energy saving, energy efficiency, law on energy saving, energy resources, conclusion of an energy service contract, compensated provision of services.

бщие положения. В соответствии со ст. 19 Федерального закона «Об энергосбережении и повышении энергетической эффективности», предметом энергосервисного договора (контракта) является осуществление исполнителем действий, направленных на энергосбережение и повышение энергетической эффективности использования энергетических ресурсов 
заказчиком ${ }^{1}$. Энергосервисный договор является разновидностью договора возмездного оказания услуг, поскольку для данного договора характерна направленность не столько на достижении определенного результата (экономии энергетических ресурсов), сколько на процессе, позволяющем достичь указанный результат путем перераспределения финансовых рисков, ведь в современных российских условиях очень важно предоставить субъектам, располагающим ограниченным бюджетом, возможность провести модернизацию с минимальными затратами. Энергосервисные услуги оказываются на возмездной основе и представляют собой процесс, имеющий определенную временную протяженность, следовательно, немаловажным следует считать решение вопросов об отнесении условий о цене и сроке к числу существенных, а также рассмотрение проблем согласования указанных условий энергосервисного договора.

Условие о цене энергосервисного договора. Законодательством предусмотрена возможность регулирования цен. Регулируемая цена - это цена товара, складывающаяся на товарном рынке при государственном воздействии на нее путем применения экономических и (или) директивных мер². Регулирование может осуществляться в виде введения как фиксированных цен, предельных цен и надбавок, так и предельных коэффициентов изменения цен, предельного уровня рентабельности и др³ . В общем нормативном порядке цена энергосервисных услуг не регулируется, следовательно, при формировании цены надлежит руководствоваться общей нормой - ст. 424 ГК РФ. В соответствии с указанной нормой, исполнение договора оплачивается по цене, установленной соглашением сторон ${ }^{4}$.

Несмотря на то, что законодатель признаёт возмездность конституирующим признаком договора возмездного оказания услуг, разновидностью которого является энергосервисный договор, положения главы 39 ГК РФ не содержат никаких специальных

\footnotetext{
${ }^{1}$ Федеральный закон от 23.11.2009 N 261-Ф3 (ред. от 28.12.2013) «Об энергосбережении и о повышении энергетической эффективности и о внесении изменений в отдельные законодательные акты Российской Федерации»: «Российская газета», N 226, 27.11.2009, ИПС «КонсультантПлюс».
}

${ }^{2}$ Ершова И.В. Предпринимательское право. М., 2002. С. 351.

${ }^{3}$ Договорное право. Книга первая. Общие положения / М. И. Брагинский, В. В. Витрянский. -3-е изд., стер. - М.:Статут, 2011. - 847 с.

${ }^{4}$ Гражданский кодекс Российской Федерации (часть первая) от 30.11.94 № 51-Ф3 (принят ГД ФС РФ 21.10.94). Собрание законодательства РФ, 05.12.1994, N 32, ст. 3301, ИПС «КонсультантПлюс». правил относительно цены. Следовательно, цена не является существенным условием договора, хотя возмездность договора и означает необходимость встречного удовлетворения. По мнению исследователей, «логика законодателя в вопросе о цене в возмездном договоре такова: в возмездном договоре цена должна присутствовать обязательно, но стороны договора не всегда должны согласовывать цену при заключении договора». В таком положении дел не следует усматривать противоречие, так как «положения ГК РФ о цене как условии договора ориентируют субъектов предпринимательской деятельности на учет рыночной ситуации и применение ими рыночных цен в совершаемых ими коммерческих операциях» ${ }^{6}$. При этом рыночной ценой товара (работы, услуги) признается цена, сложившаяся при взаимодействии спроса и предложения на рынке идентичных (а при их отсутствии- однородных) товаров (работ, услуг) в сопоставимых экономических (коммерческих) условиях ${ }^{7}$.

Иного мнения придерживается Б.И. Пугинский: «Установлено, что при отсутствии в договоре условия о цене, оплата производится по той цене, которая в момент заключения договора обычно взималась за аналогичное имущество (работу, услугу). Такой порядок неприемлем для коммерческих договоров, поскольку вносит неопределенность во взаимоотношения сторон. Определить обычно взимаемую цену на товар порой бывает довольно трудно, особенно когда дело касается нового или впервые закупаемого товара. Поэтому сторонам следует конкретно определять цену товара в договоре» ${ }^{8}$.

Б.И. Пугинский также отмечает, что «цена может использоваться как средство стимулирования к надлежащему исполнению обязательств»".

Пункт 3 ч.2 ст. 19 Закона «Об энергосбережении и повышении энергетической эффективности» предусматривает возможность включения условия об определении цены в энергосервисном договоре (контракте) исходя из показателей, достигнутых или планируемых для достижения в результате ре-

\footnotetext{
${ }^{5}$ Коммерческое (предпринимательское) право/ Под. Ред. В.Ф. Попондопуло. В 2 т. 4-е изд. Т. 1. - М., 2009. с. 435

${ }^{6}$ Там же.

${ }^{7}$ Налоговый кодекс Российской Федерации (часть первая) от 31.07.1998 N 146-ФЗ (принят ГД ФС РФ 16.07.1998). Собрание законодательства РФ, N 31, 03.08.1998, ст. 3824.

${ }^{8}$ Коммерческое право России: учебник/ Б.И. Пугинский. - 4-е изд., перераб. и доп. - М.: Издательство Юрайт; Юрайт-Издат, 2010. - 354 с. - Серия: Основы наук. С. 229.

${ }^{9}$ Там же, с. 229.
} 


\section{Право и политика $8(176) \cdot 2014$}

ализации энергосервисного договора (контракта), в том числе исходя из стоимости сэкономленных энергетических ресурсов ${ }^{10}$. Данная норма закона носит диспозитивный характер и подтверждает тезис о том, что цена не является существенным условием энергосервисного договора. Следует отметить, что условие о величине экономии энергетических ресурсов является неотъемлемой частью условия о предмете и подлежит обязательному согласованию сторонами; следовательно, и вопрос об определении цены не составит труда решить, ориентируясь на эту согласованную величину. Безусловно, такое условие о цене энергосервисного договора стимулирует исполнителя к надлежащему исполнению принятых обязательств. Принцип зависимости цены от достигнутых результатов может воплощаться в различных моделях энергосервисного договора.

Так, в мировой практике выделяют три основные модели ${ }^{11}$ :

1. Гарантирование экономии (Guaranteed savings, Chauffage);

Данная модель подразумевает финансирование мероприятий в рамках энергосервисного договора за счет заказчика. Исполнитель при этом гарантирует достижение определенных договором показателей. Таким образом, оплата услуг исполнителю зависит от того, были достигнуты гарантированные показатели или нет. В общем периоде срока действия договора выделяются этапы, в рамках которых фиксируется факт достижения показателей и производится оплата. На случай, если фактические результаты превысят согласованные показатели, для исполнителя может быть предусмотрена система бонусов. В случае недостижения согласованных показателей, исполнитель несет ответственность в рамках договора.

2. Разделение доходов от экономии (Shared savings);

В рамках такой модели исполнитель финансирует реализацию необходимых мероприятий за счет собственных или заемных средств. Сторонами согласовывается доля сэкономленных средств, которую получит исполнитель и заказчик независимо от величины достигнутых показателей.

\footnotetext{
${ }^{10}$ Федеральный закон от 23.11.2009 N 261-Ф3 (ред. от 28.12.2013) «Об энергосбережении и о повышении энергетической эффективности и о внесении изменений в отдельные законодательные акты Российской Федерации»: «Российская газета», N 226, 27.11.2009, СПС «КонсультантПлюс».

${ }^{11}$ По данным Института профессионального администрирования и комплексной энергоэффективности Минобрнауки России.[Электронный pecypc]: www.IMCEE.ru. Дата обращения: 10.12.2013.
}

3. Быстрая окупаемость (First-Out, First Pay-Out);

При использовании такой модели исполнитель за свой счет финансирует реализацию мероприятий в рамках энергосервисного договора и получает весь объем средств от полученной экономии на каждом этапе исполнения договора вплоть до того момента, пока затраты полностью не окупятся.

Закон «Об энергосбережении и повышении энергетической эффективности» не содержит императивных указаний в отношении формирования цены. Подчеркнем, что включение в договор условия об определении цены исходя из достигнутых показателей, представляется возможным, но не обязательным для сторон. Однако, императивный характер указанная норма приобретает в сфере заключения государственных или муниципальных энергосервисных контрактов. Требования к условиям энергосервисного контракта утверждены Постановлением Правительства РФ от 18.08.2010 N 636. П. 5 Постановления в качестве обязательного требования к энергосервисному контракту устанавливает наличие положения, предусматривающего, что обязательство исполнителя по обеспечению экономии расходов заказчика на поставки энергетических ресурсов считается исполненным, если размер экономии (доли размера экономии), достигнутой в результате исполнения контракта, в натуральном выражении равен или больше размера экономии (доли размера экономии) энергетического ресурса, указанного в контракте ${ }^{12}$. Пункт 17 Постановления предусматривает уплату неустойки в качестве меры ответственности исполнителя за неисполнение или ненадлежащее исполнение обязательства по достижению определенной в контракте доли размера экономии в течение соответствующего календарного периода. Наряду с ответственностью, рассматриваемым нормативным актом установлен механизм распределения между сторонами контракта дополнительной экономии энергетического ресурса. Таким образом, в сфере государственных контрактов порядок формирования цены энергосервисного контракта установлен нормативно ${ }^{13}$. Для указанной сферы законодателем избрана модель кон-

\footnotetext{
${ }^{12}$ Постановление Правительства РФ от 18.08.2010 N 636 (ред. от $01.10 .2013)$ «О требованиях к условиям энергосервисного контракта и об особенностях определения начальной (максимальной) цены энергосервисного контракта (цены лота)».

${ }^{13}$ Постановление Правительства РФ от 18.08.2010 N 636 (ред. от 01.10.2013) «О требованиях к условиям энергосервисного контракта и об особенностях определения начальной (максимальной) цены энергосервисного контракта (цены лота)».
} 
тракта, предусматривающая формирование цены договора по принципу гарантированной экономии.

Аналогичная модель рекомендована и для заключения энергосервисных договоров в жилищно-коммунальной сфере. Так, цену энергосервисного договора предлагается определять как стоимость сэкономленных энергоресурсов, или исходя из величины плановой или фактической экономии в стоимостном выражении, рассчитанной на основе цен (тарифов) на коммунальный ресурс. Расчеты по энергосервисному договору осуществляются исключительно после фактически достигнутой и подтвержденной экономии коммунальных ресурсов в соответствующем периоде. Ответственность исполнителя по энергосервисному договору наступает за неисполнение своих обязательств, в том числе в случае, когда исполнитель не обеспечил достижение согласованной при подписании договора плановой величины экономии коммунального ресурса ${ }^{14}$.

Следует отметить, что в остальных случаях порядок формирования цены энергосервисного договора нормативными актами не установлен, что позволяет исполнителям и заказчикам избрать любую удобную для них модель.

Анализ нормативных актов позволяет сделать вывод о том, что в Российской Федерации в настоящий период времени воспринята модель энергосервисного договора (контракта), предусматривающая формирование цены договора исходя из факта достижения/не достижения гарантированной экономии. Определение цены происходит на основе стоимости объема сэкономленных энергетических ресурсов. Следовательно, в данном случае соотношение стоимости и цены переводится в правовое поле и приобретает правовое значение ${ }^{15}$.

Срок энергосервисного договора. Достижение необходимых показателей экономии энергоресурсов происходит поэтапно, поэтому срок энергосервисного договора имеет определяющее значение. В гражданском праве под сроком понимается момент или период времени, наступление или истечение которых влечет определенные правовые последствия. Наступление (истечение) сроков носит объективный характер и не зависит от воли субъектов правоотношений, поэтому

\footnotetext{
${ }^{14}$ Приказ Минрегиона России от 27.06.2012 N 252 «Об утверждении примерных условий энергосервисного договора, направленного на сбережение и (или) повышение эффективности потребления коммунальных услуг при использовании общего имущества в многоквартирном доме» (Зарегистрировано в Минюсте России 27.08.2012 N 25277).

${ }^{15}$ Коммерческое (предпринимательское) право/ Под. Ред. В.Ф. Попондопуло. В 2 т. 4-е изд. Т. 1. - М., 2009.с. 413
}

в классификации юридических фактов срок относят к категории событий. Правила исчисления сроков содержатся в главе 11 ГК РФ. Согласно ст. 190 ГК РФ, срок определяется календарной датой или истечением периода времени, который исчисляется годами, месяцами, неделями, днями или часами. Срок может определяться также указанием на событие, которое должно неизбежно наступить ${ }^{16}$. Из смысла положение главы 22 ГК РФ, посвященной исполнению обязательств, следует, что обязательства должны исполняться надлежащим образом, в соответствии с условиями обязательства и требованиями закона, иных правовых актов, а при отсутствии таких условий и требований - в соответствии с обычаями делового оборота или иными обычно предъявляемыми требованиями ${ }^{17}$.

Законом «Об энергосбережении и повышении энергетической эффективности» срок энергосервисного договора, наряду с его предметом, отнесен к числу существенных условий. Отметим, что необходимо различать срок действия договора как обязательственного правоотношения и срок как элемент договора. Момент начала действия договора определяется моментом его заключения. В соответствии со ст. 432 ГК РФ, договор считается заключенным, если между сторонами, в требуемой в подлежащих случаях форме, достигнуто соглашение по всем существенным условиям договора ${ }^{18}$. Окончание действия договора связано с исполнением сторонами обязательств по данному договору. Срок действия договора и срок-элемент договора могут не совпадать.

Так, в соответствии с ч.2 ст. 19 Закона, в энергосервисный договор (контракт) обязательно включается условие о сроке действия энергосервисного договора (контракта), который должен быть не менее чем срок, необходимый для достижения установленной энергосервисным договором (контрактом) величины экономии энергетических ресурсов ${ }^{19}$.

На наш взгляд, в приведенной формулировке происходит смешение понятия об общем сроке действия

\footnotetext{
${ }^{16}$ Гражданский кодекс Российской Федерации (часть первая) от 30.11.94 № 51-Ф3 (принят ГД ФС РФ 21.10.94). Собрание законодательства РФ, 05.12.1994, N 32, ст. 3301, ИПС «КонсультантПлюс». ${ }^{17}$ Там же.

${ }^{18}$ Гражданский кодекс Российской Федерации (часть первая) от 30.11.94 № 51-Ф3 (принят ГД ФС РФ 21.10.94). Собрание законодательства РФ, 05.12.1994, N 32, ст. 3301, ИПС «КонсультантПлюс».

${ }^{19}$ Федеральный закон от 23.11.2009 N 261-Ф3 (ред. от 28.12.2013) «Об энергосбережении и о повышении энергетической эффективности и о внесении изменений в отдельные законодательные акты Российской Федерации»: «Российская газета», N 226, 27.11.2009, СПС «КонсультантПлюс».
} 


\section{Право и политика $8(176) \cdot 2014$}

договора-обязательства и понятие о сроке, отведенном сторонами на исполнение конкретной обязанности. Логично предположить, что законодатель имел ввиду срок, в течение которого должник совершает действие, составляющее содержание его обязанности.

В подзаконных нормативных актах упоминаются различные сроки, относящиеся к энергосервисному договору. Так, в Постановлении Правительства РФ «О требованиях к условиям энергосервисного контракта и об особенностях определения начальной (максимальной) цены энергосервисного контракта (цены лота)» ${ }^{20}$ значится «срок на выполнение мероприятия, направленного на энергосбережение», «срок действия контракта», «срок достижения предусмотренного контрактом размера экономии», «период достижения долей размера экономии», «срок оплаты заказчиком долей размера экономии», «срок исполнения контракта». Примерные условия энергосервисного договора, направленного на сбережение и (или) повышение эффективности потребления коммунальных услуг при использовании общего имущества в многоквартирном доме 21 содержат следующие упоминания о сроке: «срок, необходимый для выполнения предусмотренных договором работ (услуг)», «срок определения достигнутой величины экономии коммунальных ресурсов», «срок оплаты исполнителю цены договора» и «гарантийный срок».

Статья 432 ГК РФ устанавливает правило, в соответствии с которым существенным условием договора является условие необходимое для данного договора. Без такого условия нельзя обойтись - договор, в котором оно отсутствует, попросту невозможно исполнить. Ранее доказывалось, что основной целью услуги в рамках энергосервисного договора является не только достижение заказчиком экономии энергетических ресурсов, но и поддержание достигнутого уровня. Более того, неотъемлемой частью предмета энергосервисного договора является определенная величина экономии. В достижении данного показателя заинтересован как исполнитель (ведь от этого зависит и величина вознаграждения, и возможность применения штрафных

\footnotetext{
${ }^{20}$ Постановление Правительства РФ от 18.08.2010 N 636 (ред. от 01.10.2013) «О требованиях к условиям энергосервисного контракта и об особенностях определения начальной (максимальной) цены энергосервисного контракта (цены лота)».

${ }^{21}$ Приказ Минрегиона России от 27.06.2012 N 252 «Об утверждении примерных условий энергосервисного договора, направленного на сбережение и (или) повышение эффективности потребления коммунальных услуг при использовании общего имущества в многоквартирном доме» (Зарегистрировано в Минюсте России 27.08.2012 N 25277).
}

санкций), так и заказчик. Поэтому, на наш взгляд, определяющим для энергосервисного договора является срок, по истечении которого должна быть достигнута согласованная сторонами величина экономии энергетических ресурсов. Но срок как существенное условие договора может охватывать не только временной период, необходимый для достижения конкретного показателя, но и последующий период поддержания достигнутого эффекта. Безусловно, в рамках договора могут быть выделены периоды, но, по нашему мнению, установление сроков наступления таких периодов определяется сторонами, скорее, для корректировки действий в рамках договора и осуществления текущих расчетов. Следовательно, отсутствие согласования таких периодов в рамках основного срока не должно влечь признание договора незаключенным.

Выводы: 1) Цена энергосервисного договора не относится к числу его существенных условий и не подвергается государственному регулированию. Характерной особенностью энергосервисного договора следует считать возможность установления цены в зависимости от величины экономии энергетических ресурсов, достигнутой в результате осуществления энергосберегающих мероприятий в рамках энергосервисного договора; указанная величина. в свою очередь. подлежит согласованию сторонами. 2) Срок энергосервисного договора, наряду с предметом договора, относится к числу существенных условий. Для того, чтобы заключить договор, стороны обязаны установить срок, по истечении которого должна быть достигнута согласованная сторонами величина экономии энергетических ресурсов.

\section{Библиография:}

1. Федеральный закон от 23.11.2009 N 261-Ф3 (ред. от 28.12.2013) «Об энергосбережении и о повышении энергетической эффективности и о внесении изменений в отдельные законодательные акты Российской Федерации»: «Российская газета», N 226, 27.11.2009, ИПС «КонсультантПлюс».

2. Гражданский кодекс Российской Федерации (часть первая) от 30.11.94 № 51-Ф3 (принят ГД ФС РФ 21.10.94). Собрание законодательства РФ, 05.12.1994, N 32, ст. 3301, ИПС «КонсультантПлюс».

3. Постановление Правительства РФ от 18.08.2010 N 636 (ред. от 01.10.2013) «О требованиях к условиям энергосервисного контракта и об особен- 
ностях определения начальной (максимальной) цены энергосервисного контракта (цены лота)».

4. Приказ Минрегиона России от 27.06.2012 N 252 «Об утверждении примерных условий энергосервисного договора, направленного на сбережение и (или) повышение эффективности потребления коммунальных услуг при использовании общего имущества в многоквартирном доме» (Зарегистрировано в Минюсте России 27.08.2012 N 25277).

5. Коммерческое (предпринимательское) право/ Под. Ред. В.Ф. Попондопуло. В 2 т. 4-е изд. Т. 1. М., 2009.c. 413

6. Ершова И.В. Предпринимательское право. М., 2002. C. 351.

7. Договорное право. Книга первая. Общие положения / М. И. Брагинский, В. В. Витрянский. - 3-е изд., стер. - М. :Статут, 2011. - 847 с.

8. Коммерческое (предпринимательское) право/ Под. Ред. В.Ф. Попондопуло. В 2 т. 4-е изд. Т. 1. - М., 2009. с. 435 5.Коммерческое право России: учебник/ Б.И. Пугинский. - 4-е изд., перераб. и доп. - М.: Издательство Юрайт; Юрайт-Издат, 2010. - 354 с. - Серия: Основы наук. С. 229.

9. Васильченко А.И. Деятельность по энергосбережению: понятие и признаки // Право и политика. - 2014. - 4. - C. 505-511. DOI: 10.7256/18119018.2014.4.11675.

10. Курбанов Р.А.. Правовое регулирование угольной промышленности и угольной электроэнергетики (Северная Америка) // Политика и Общество. - 2014. - № 5. - C. 104-107. DOI: 10.7256/18128696.2014.5.11631

11. Курбанов Р.А.. Правовое регулирование инвестиций в энергетический сектор стран Северной Америки // Политика и Общество. - 2014. - № 4. - C. 104-107. DOI: 10.7256/1812-8696.2014.4.11630

12. Дубовик О.Л.. Тенденции правового регулирования энергосберегающих технологий в европейском праве // Административное и муниципальное право. - 2012. - № 4. - С. 104-107.

13. Курбанов Р.А.. Правовое регулирование в сфере разведки, добычи и транспортировки нефти и газа (США) // Политика и Общество. - 2014. - № 3. - C. 104-107. DOI: 10.7256/18128696.2014.3.11629

14. Р.А. Курбанов. Снабжение энергоносителями предприятий атомной энергетики и инвестиции в атомную энергетику как отдельные аспекты права ЕС в сфере атомной энергетики // Политика и Общество. - 2012. - № 12. - С. 104-107.
15. Р.А. Курбанов. Правовое обеспечение бесперебойности поставок энергоносителей в Европейском Союзе // Политика и Общество. - 2012. - № 11. - C. 104-107.

16. Р. А. Курбанов, Т. М. Шамба. Энергетическое право Европейского Союза // Право и политика. 2012. - № 5. - С. 104-107

17. Васильченко А.И. Деятельность по энергосбережению: понятие и признаки // Право и политика. - 2014. - 4. - С. 505 - 511. DOI: 10.7256/18119018.2014.4.11675.

\section{References (transliteration):}

1. Ershova I.V. Predprinimatel'skoe pravo. M., 2002. S. 351 .

2. Vasil'chenko A.I. Deyatel'nost' po energosberezheniyu: ponyatie i priznaki // Pravo i politika. - 2014. - 4 . - C. 505-511. DOI: 10.7256/1811-9018.2014.4.11675.

3. Kurbanov R.A.. Pravovoe regulirovanie ugol'noi promyshlennosti i ugol'noi elektroenergetiki (Severnaya Amerika) // Politika i Obshchestvo. - 2014. - № 5. - S. 104-107. DOI: 10.7256/1812-8696.2014.5.11631

4. Kurbanov R.A.. Pravovoe regulirovanie investitsii v energeticheskii sektor stran Severnoi Ameriki // Politika i Obshchestvo. - 2014. - № 4. - S. 104-107. DOI: 10.7256/1812-8696.2014.4.11630

5. Dubovik O.L.. Tendentsii pravovogo regulirovaniya energosberegayushchikh tekhnologii v evropeiskom prave // Administrativnoe i munitsipal'noe pravo. 2012. - № 4. - S. 104-107.

6. Kurbanov R.A.. Pravovoe regulirovanie v sfere razvedki, dobychi i transportirovki nefti i gaza (SShA) // Politika i Obshchestvo. - 2014. - № 3. - S. 104-107. DOI: 10.7256/1812-8696.2014.3.11629

7. R.A. Kurbanov. Snabzhenie energonositelyami predpriyatii atomnoi energetiki i investitsii $\mathrm{v}$ atomnuyu energetiku kak otdel'nye aspekty prava ES v sfere atomnoi energetiki // Politika i Obshchestvo. - 2012. - № 12. - S. 104-107.

8. R.A. Kurbanov. Pravovoe obespechenie bespereboinosti postavok energonositelei v Evropeiskom Soyuze // Politika i Obshchestvo. - 2012. - № 11. - S. 104-107.

9. R. A. Kurbanov, T. M. Shamba. Energeticheskoe pravo Evropeiskogo Soyuza // Pravo i politika. - 2012. - № 5. - S. 104-107

10. Vasil'chenko A.I. Deyatel'nost' po energosberezheniyu: ponyatie i priznaki // Pravo i politika. - 2014. - 4 . - C. 505 - 511. DOI: 10.7256/1811-9018.2014.4.11675. 